\title{
The Impact of the Air-Conditioning Systems on the Urban Microclimate of Beirut City
}

\author{
Z. Ghaddar ${ }^{1}$, K. Ghali ${ }^{1}$ and N. Ghaddar ${ }^{1}$ \\ ${ }^{1}$ Department of Mechanical Engineering \\ FEA, American University of Beirut, P.O. Box 11-0236, Beirut 1107-202, Lebanon \\ Phone number: +961 1 340340, Ext: 3438, e-mail: zng02@mail.aub.edu, ka04@aub.edu.lb, farah@aub.edu.lb
}

\begin{abstract}
The urban heat island consists of the increase in the ambient temperature in urban areas with respect to their rural surroundings, due to artificial modifications of the natural land cover. As a result, significant increase in the demand on cooling loads occurs in cities during summer, inducing more energy consumption in buildings. Furthermore, air-conditioning systems release anthropogenic waste heat to outdoor intensifying the urban heat island. Therefore, an interactive relation exists between the heat islands formation and the cooling systems as well as mutual impacts. Hence, the contribution of the air-conditioning systems to the urban heat island is assessed through an appropriate numerical simulation for Beirut city. It is found that the intensive use of air conditioning systems in Beirut during summer could rise the street air temperature of about $0.8^{\circ} \mathrm{C}$ in the daytime and up to $4.7^{\circ} \mathrm{C}$ in the nighttime.
\end{abstract}

\section{Key words}

Key words: Urban Heat Island, Air-Conditioning, Urban Microclimate, Energy Consumption and Anthropogenic Waste Heat.

\section{Introduction}

Urban heat islands consists of urban areas with higher temperature comparing to their rural surroundings due to artificial modifications of the natural land cover [1]. The increase in outdoor temperature increases significantly the cooling loads, and consequently the buildings energy consumption, especially during the summer. In Athens, it was found that the cooling load may become doubled, and the peak electricity load for cooling tripled, due to the urban heat island [2].

Furthermore, the operation of air-conditioning systems with higher loads due to the heat island effect causes more waste heat releases from their condensers to the outdoor, thus contributing to the intensification of urban heat islands. These problems promote extensive research to comprehend the urban heat island phenomenon and its contributing factors, such as air-conditioning system anthropogenic waste heat, and highlight the importance of finding a comprehensive methodology to assess the contribution of air-conditioning systems heat in the urban heat island intensification, in order to be able to develop the proper mitigation policies. The numerical simulation approach was adopted by researchers in their studies for several cities subjected to different climates and civilian characters. A study for Paris city investigated the impact of various air-conditioning systems in the heat waves of Paris [2]. In a study for Tokyo, the increase in cooling energy demands due to heat island is evaluated [3]. These studies were based on numerical simulation using an atmospheric model along with a model for the urban microclimate and a model of the cooling energy in buildings.

Climates models are mainly classified to meso-scale and micro-scale models. The meso-scale solves large-scale interactions by Navier Stockes equations in a 3D grid of resolution of few kilometers, ignoring the details of the urban canopy supposed aerodynamic roughness [5]. Micro-scale models solves, based on the Oke's concept [6], the urban surface energy balance equation in a horizontal grid limited to few kilometers and a vertical grid limited to the urban canopy layer height roughly above the roof level. The urban geometry is simplified by a block of similar buildings arranged in an array form. The model computes mainly the air temperature in the canyon.

In this study, an atmospheric simulation over Beirut city is performed for the summer period, where the heat island strengthens. Beirut has a hot and humid climate in the summer, thus the use of air-conditioning systems in the summer becomes maximal. Hence, the aim of this study is to assess the contribution of the air-conditioning anthropogenic waste heat in the urban heat island intensification in Beirut city. This reveals the effect of the current use of air-conditioning systems in Beirut modifying the urban microclimate. It also allows to evaluate the potential of applying a mitigation policy at the air-conditioning systems level citywide in alleviating urban heat islands rather than just reducing the cooling energy consumption. 


\section{Numerical Simulation Models}

A numerical simulation of the urban microclimate over Beirut city is performed using coupled meso- and microscale models. MESO-NH software [7] is used to solve the meso-scale atmospheric problem, coupled with SURFEX packages including the Town Energy Balance model (TEB) [8] used to solve the micro-scale problem over urban regions. Furthermore, TEB includes a simplified Building Energy Model (BEM) [9] used to solve the buildings cooling energy consumption and the resultant waste heat to the outdoor. The MESO-NH, TEB, and BEM combination models the relationships between the building, the city, and the atmosphere levels interactively.

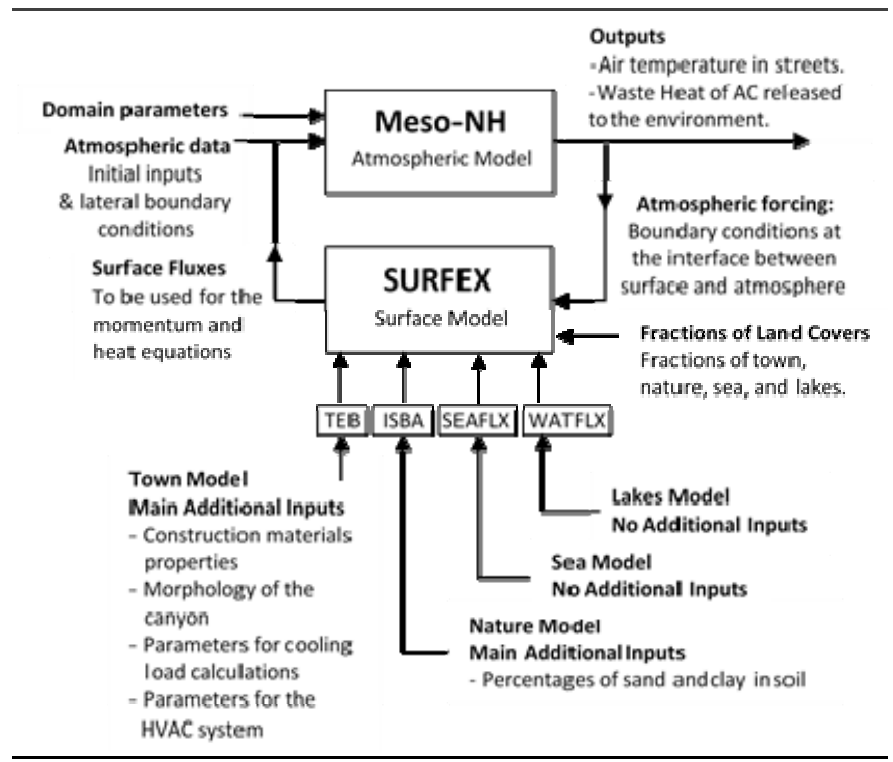

Figure 1 - Interaction between the surface and atmosphere model.

Figure 1 shows a chart that illustrates the interaction between Meso-NH and SURFEX, as well as the inputs of the various models. SURFEX is a set of four surfaceatmosphere energy-exchange models that simulates the physical processes of each surface type, and provide their fluxes to the atmospheric model Meso-NH. These surface types, or land covers, are the vegetation (nature), urban areas (town), inland water (lakes), and seas and oceans (sea). Each land area is composed of fractions of these four land covers. Data are exchanged between Meso-NH and SURFEX during each model time step. Each surface mesh receives from Meso-NH model the atmospheric forcing data, consisting of the air temperature at the top of the surface canopy level, specific humidity, horizontal wind components, pressure, total precipitation, long-wave radiation, shortwave direct and diffuse radiations. In return, SURFEX computes the averaged fluxes for momentum, sensible and latent heat required for the momentum and heat equations that Meso-NH solves, and then sends these quantities aggregated back to Meso-NH, according to the following equation:

$F_{\text {surface }}=f_{\text {town }} F_{\text {town }}+f_{\text {nature }} F_{\text {nature }}+f_{\text {sea }} F_{\text {sea }}+f_{\text {lake }} F_{\text {lake }}$

Where $F_{\text {surface }}, F_{\text {town }}, F_{\text {nature }}, F_{\text {sea }}, F_{\text {lake }}$ are the fluxes of the entire surface, the town, the nature, the sea, and the lake respectively. $f_{\text {town }}, f_{\text {nature }}, f_{\text {sea }}, f_{\text {lake }}$ are their fractions.

The vegetation scheme in SURFEX is the Interaction between Soil Biosphere and Atmosphere (ISBA) model [10]. The main physical processes for the vegetation schemes can be characterized by four primary parameters specified by spatial distribution; the percentages of sand and clay in the soil, the dominant vegetation type, and the land-sea mask [11]. The sea and oceans scheme is Sea Flux, and the inland water scheme, like rivers and lakes, is Water Flux. The urban areas scheme is TEB.

A scheme of TEB, BEM, and MESO-NH models is illustrated in figure 2. TEB models the urban geometry as a simple set of street canyons existing equally in all directions. TEB simulates the exchanges of heat and water from road, wall, and roof surfaces. The TEB simulation concept is based on an energy balance established on the outer surfaces of both wall and roof, taking into account the solar and infrared net radiation, the convective heat flux, and the water evaporation for the roof. The evolution of the wall and roof internal temperatures by heat conduction is then solved at each time step by the model. Finally, exchanges with the air inside the building are calculated from the air temperature inside the building. The latter is described in a simplified way to account for the inertia of buildings and the temperatures of the inner surfaces of walls and roofs [12].

The Building Energy Model (BEM) [9] is implemented in TEB to include the representation of the some additional processes of building energetics; the solar and internal heat gains, the heat transmission through the envelop, the heat exchange by infiltration and ventilation. In addition, it include a model for heating and cooling load and systems.

The simulation is performed to predict the air temperature in the street level in Beirut in different hours during a typical hot summer day. The contribution of airconditioning anthropogenic waste heat in intensifying the urban heat island is then assessed by the increase in the air temperature resultant from the use of air-conditioning systems in the city. 


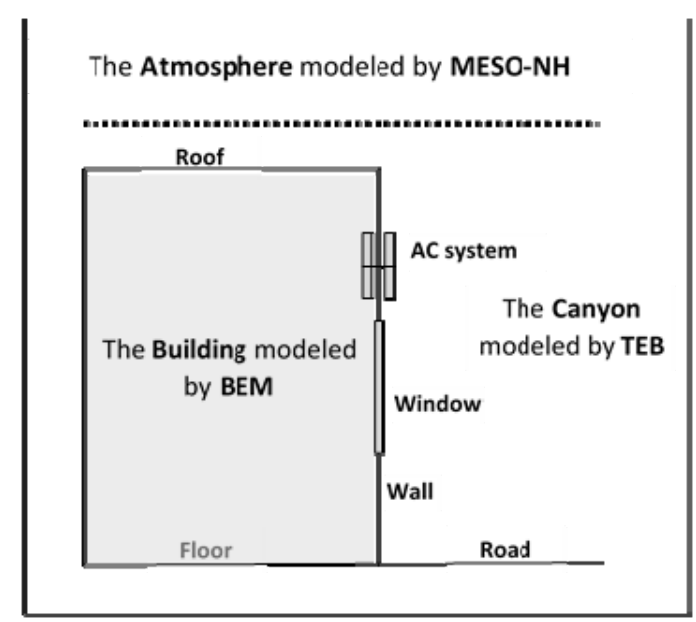

Figure 2: Scheme of TEB, BEM, and MESO-NH models.

\section{Case Study}

Once the simulation tool is determined, a case study is undergone for Beirut city. Beirut is located in the eastern Mediterranean coast and is governed by a hot and humid climate in the summer. Beirut is the capital of Lebanon, including most of the administrative and economical centers in the country. It is characterized by a high density of building and high air-conditioning demands in the summer especially in July and August.

The simulation runs for a period of 24 hours, starting from 4 August at 6:00 AM (UTC) until 5 August at 6:00 AM (UTC). The horizontal grids consists of two nested grids of different size and resolution. Nesting is usually used to focus computations on a small area with mesh of high resolution using the data on a larger area with a mesh of lower resolution. The horizontal grids are of size $200 \mathrm{~km} \times$ $200 \mathrm{~km}$ with $4 \mathrm{~km}$ resolution, and $16 \mathrm{~km} \times 16 \mathrm{~km}$ with 1 $\mathrm{km}$ resolution, representing the grid of Lebanon, and Beirut respectively. The vertical grid for the two horizontal grids is of height about $21 \mathrm{~km}$, divided to 50 division, fine at the bottom and coarse at the top. Initialization and lateral boundaries conditions are made through using the analysis data of weather forecasts from ECMWF database. Fractions of the four land covers: town, nature, sea and lakes, are of $1 \mathrm{~km}$ resolution based on Ecoclimap database [12] and aerial photos.

TEB and BEM require a set of morphological parameters, materials properties, and air-conditioning system related variables. The values of the inputs provides good representation of the particular case of Beirut city with its urban characteristics. The morphological parameters values are obtained for the studied region of Beirut based on official statistics and aerial photos. They include the density of buildings, the buildings height, the facade glazing ratio, and the roughness length. The construction material properties for buildings walls, roofs, floors, and the road are also determined, and include the thermal conductivity of the constituting materials, their volumetric capacity, their thickness, and the albedo and the emissivity of the outermost material. In addition, the cooling system parameters such as the set point temperature and relative humidity for cooling, the rated capacity, mass flow rate, and COP for the system are specified. Estimated values for the anthropogenic heat of the transportation sector is added to account for their influence.

Given the proper inputs, the influence of the airconditioning systems in raising the air temperature in the streets of Beirut city is evaluated by comparing the results of two case simulations, one representing the real case and another representing a proposed case where the anthropogenic heat releases of the air-conditioning systems where removed. Finally, conclusions on the contribution of the cooling systems in the aggravation of the urban heat island in Beirut city are drawn.

\section{Results}

The main results are summarized in Table 1 . The table shows the street temperature in $\left({ }^{\circ} \mathrm{C}\right)$ predicted by the model for two cases; one representing the real case where the AC systems in the city operate, and another proposed case where the AC systems are considered disabled. The temperatures are for a mesh corresponding to a specific district in Beirut; Hamra district, considered representative of Beirut. In fact, this district is characterized by including a variety of buildings types: residential, commercial, office buildings..., which requires the use of AC intensively and all over the day. The street temperatures are obtained every three hours from 4 August at 6:00 AM (UTC) until 5 August at 6:00 AM (UTC). The contribution of air-conditioning anthropogenic waste heat in the urban heat island intensity is then calculated as the difference of temperatures between the two cases. The results are shown in Table 1.

Table 1 - Street temperature for the two simulations and the predicted contribution of AC in the urban heat island intensity.

\begin{tabular}{|c|c|c|c|c|c|c|c|c|c|}
\hline & \multicolumn{6}{|c|}{ 4-Aug } & \multicolumn{2}{|c|}{ 5-Aug } \\
\hline & & $6: 00$ & 9:00 & $12: 00$ & $15: 00$ & $18: 00$ & 21:00 & $0: 00$ & $6: 00$ \\
\hline \multirow{3}{*}{$\begin{array}{c}\text { Street } \\
\text { Temperature } \\
\left({ }^{\circ} \mathrm{C}\right)\end{array}$} & $\begin{array}{c}\text { AC disabled } \\
\text { (Proposed case) }\end{array}$ & 34.9 & 38.2 & 37.9 & 34.7 & 29.5 & 27.4 & 26.1 & 33.9 \\
\hline & $\begin{array}{l}\text { AC enabled } \\
\text { (Real case) }\end{array}$ & 34.9 & 38.7 & 38.5 & 35.6 & 33 & 31.8 & 30.8 & 34.9 \\
\hline & UHII & 0 & 0.5 & 0.6 & 0.9 & 3.5 & 4.4 & 4.7 & 1 \\
\hline
\end{tabular}

Table 1 shows the street temperature increase due airconditioning heat with respect to daytime. It is noticed that it increases significantly in the night, because the heat is usually stored during the day and re-emitted during the night. This feature appears particularly in cities due to the high storage capacity of the construction materials such as concrete and asphalt versus the vegetation. Another factor is attributed to the higher turbulence during the day. Briefly, the air-conditioning waste heat causes an increase of the street temperature from $0.5^{\circ} \mathrm{C}$ in the day up to $4.7^{\circ} \mathrm{C}$ in the night.

\section{Conclusion}


At the end, this work demonstrated the influence of the anthropogenic heat of air conditioning systems in Beirut in raising the ambient temperature in the cities. Even though it is varying along the day, it could reach high levels, especially during the night, which cannot be neglected. This reveals the seriousness of the problem, and imposes more research and persistent work to find convenient mitigation strategies concerning the anthropogenic waste heat of air conditioning.

\section{References}

[1] H. E. Landsberg, "The Urban Climate”, Academic Press, New York, 1981.

[2] M. Santamouris, N. Papanikolaou, I. Licada, I. Koronakis, C. Georgakis, A. Argiriou, et al., "On the impact of urban climate on the energy consumption of buildings”, Solar Energy 70(3), 2001, 201-216.

[3] B. Tremeac, P. Bousquet, C. De Munck, G. Pigeon, V. Masson, C. Marchadier, M. Merchat, P. Poeuf, F. Meunier, "Influence of air-conditioning management on heat island in Paris air street temperatures”, Applied Energy 95, 2012, 102-110.

[4] Y. Kikegawa, Y. Genchi, H. Yoshikado, H. Kondo, "Development of a numerical system toward comprehensive assessment of urban warming countermeasures including their impacts upon the urban buildings' energy-demands”, Applied Energy 76, 2003, 449-466.

[5] P. A. Mirzaei, F. Haghighat, "Approaches to study Urban Heat Island Abilities and limitations", Building and Environment 45, 2010, 2192-2201.

[6] T. R. Oke, Boundary Layer Climates, Second Edition, Routledge, 1987.

[7] J. P. Lafore, J. Stein, N. Asencio, P. Bougeault, V. Ducrocq, J. Duron, C. Fischer, P. Hereil, P. Mascart, V. Masson, J. P. Pinty, J. L. Redelsperger, E. Richard, JV-G. de Arellano, “The MESO-NH atmospheric simulation system. Part I: adiabatic formulation and control simulations”, Annales Geophysicae 16, 1998, 90-109.

[8] V. Masson, "A physically-based scheme for the urban energy budget in atmospheric models”, Boundary-Layer Meteorology 94, 2000, 357-397.

[9] B. Bueno, G. Pigeon, L. Norford, K. Zibouche, C. Marchadier, "Development and evaluation of a building energy model integrated in the TEB scheme”, Geoscience Model Development 5, 2012, 433-448.

[10] J. Noilhan, J. F. Mahfouf, "The ISBA land surface parameterization scheme”, Global and Planetary Change 13, 1996, 145-159.

[11] P. Le Moigne, A. Boone, S. Belamari, E. Brun, J. C. Calvet, B. Decharme, S. Faroux, A. L. Gibelin, H. Giordani, S. Lafont, C. Lebeaupin, J. F. Mahfouf, E. Martin, V. Masson, D. Mironov, S. Morin, J. Noilhan, P. Tulet, B. Van Den Hurk, V. Vionnet, “Surfex Scientific Documentation”, version 7.2, Issue 2, 2012, 118.

[12] V. Masson, C. S. B. Grimmond, T. R. Oke, "Evaluation of the Town Energy Balance (TEB) scheme with direct measurements from dry districts in two cities”, Journal of Applied Meteorology 41, 2002, 1011-1026.
[13] V. Masson, J. L. Champeaux, F. Chauvin, C. Meriguet, G. Pigeon, "Ecoclimap: a global database of land surface parameters at 1-km resolution in meteorological and climate models”, Journal of climate 16(9), 2003, 1261-1282. 